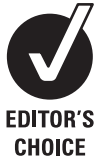

${ }^{1}$ Health Protection Agency West Midlands, Regional Surveillance Unit, Birmingham, UK;

${ }^{2}$ Arrowside Unit, Alexandra Hospital, Redditch, UK;

${ }^{3}$ Hawthorn House, Heartlands Hospital, Birmingham, UK;

${ }^{4}$ Health Protection Agency West Midlands East Health Protection Unit, Birmingham, UK; ${ }^{5}$ Whittall Street Clinic, Birmingham, UK; ${ }^{6}$ Health Protection Agency, West Midlands Public Health Laboratory, Heartlands and Solihull NHS Trust (Teaching), Birmingham, UK; ${ }^{7}$ Health Protection Agency, West Midlands North Health Protection Unit, Stafford, UK

Correspondence to:

Dr Babatunde Olowokure, Consultant Epidemiologist, Health Protection Agency, Regional Surveillance Unit, 9th floor, Ladywood House, 45

Stephenson Street, Birmingham B2 4DY; babatunde.

olowokure@hpa.org.uk

Accepted 26 March 2008

Published Online First

27 June 2008

\title{
Trends in sexually transmitted infections (other than HIV) in older people: analysis of data from an enhanced surveillance system
}

\author{
A T Bodley-Tickell, ${ }^{1}$ B Olowokure, ${ }^{1}$ S Bhaduri, ${ }^{2}$ D J White, ${ }^{3}$ D Ward, ${ }^{4}$ J D C Ross, ${ }^{5}$ \\ G Smith, ${ }^{6}$ H V Duggal, ${ }^{7}$ P Goold, ${ }^{5}$ on behalf of the West Midlands STI \\ Surveillance Project
}

\section{ABSTRACT}

Objective: This study examines the distribution of selected sexually transmitted infections (STIs) in older people (aged $\geqslant 45$ years) attending genitourinary medicine (GUM) clinics in the West Midlands, UK.

Methods: Analysis of data from the regional enhanced STI surveillance system for the period 1996-2003. Selected STIs were chlamydia, genital herpes, genital warts, gonorrhoea and syphilis.

Results: Altogether, 4445 STI episodes were reported among older people during the study period. Between 1996 and 2003 older people accounted for 3.7\% and $4.3 \%$, respectively, of all GUM clinic attendances. The rate of STls in older people more than doubled in 2003 compared with $1996(p<0.0001)$. Rates for all five selected diagnoses were significantly higher in 2003 compared to 1996. A significantly increasing trend over time was seen overall $(p<0.0001)$ and for each of the selected diagnoses. Overall, males and those aged 55-59 years of age were significantly more likely to be affected. Conclusions: This study provides evidence of significant increases in attendance at GUM clinics by older people. Although it is recognised that young people should remain the focus of sexual health programmes, the results indicate that sexual risk-taking behaviour is not confined to young people but also occurs among older people. There is therefore a need to develop and implement evidence-based multifaceted sexual health programmes that while aiming to reduce STI transmission among all age groups should include interventions aimed specifically at older people and address societal and healthcare attitudes, myths and assumptions about sexual activity among older people.

There is currently unprecedented public and political interest in sexual health. The UK Government has published both a National Strategy for Sexual Health and HIV ${ }^{1}$ and included sexual health in the "Choosing Health" Public Health White Paper. ${ }^{2}$

However, as sexually transmitted infections (STIs) predominately occur in people aged less than 45 years of age, these policies concentrate on this particular age group. Increasing rates of infection, increased public awareness of STIs and the drive to improve and expand the provision of sexual health services have all served to focus attention on STIs. Indeed, data from the Health Protection Agency (HPA) indicate that in the past decade there has been an increasing number of people attending genitourinary medicine (GUM) clinics in England and Wales and that an increasing proportion of these are aged more than 45 years. ${ }^{3}$ Despite the increased political, public and professional recognition of the public health importance of STIs, and the increasing number of visits to GUM clinics by people aged 45 years and over, there remain few studies addressing STIs in older age groups. Previous UK studies specifically on older people have tended to be cross-sectional in nature, limited to single GUM clinics and subject to small numbers. ${ }^{45}$

Given the current increase in STIs in the UK and the lack of published data to inform sexual health services and meet local needs for older people, this study describes the epidemiology of STIs, other than HIV, in people aged 45 years or more attending GUM clinics in the West Midlands, UK, between 1996 and 2003.

\section{METHODS}

National statistics on STIs in the UK are compiled from forms completed by GUM clinics known as form KC60 returns. All GUM clinics in England and Wales have a statutory obligation to complete this form and assign each diagnosis at a GUM clinic a specific KC60 code, which defines the condition or conditions with which the patient presented, but this is only available in aggregate form. Aggregation of the dataset limits its use as there is insufficient information on risk factors with which to target interventions.

The West Midlands regional enhanced STI surveillance system commenced during 1997 using data collected retrospectively for 1996. In subsequent years, data have been collected annually on a retrospective basis. The methodology has been described previously. ${ }^{6}$ Briefly, the system collects disaggregate, individual anonymised data from 19 of the 21 GUM clinics in the region. These data are routinely collected during patient consultations, coded and entered onto a computerised clinical data management system. From each clinic system, epidemiological, demographical and clinical data are downloaded. The participating clinics use several different coding systems and these are standardised before any analyses are carried out. Data collected were stored on a secure, passwordprotected database. Confidentiality is a prime concern of the project and all data are handled in accordance with the Data Protection Act and Caldicott guidelines. ${ }^{7}$ 
The five diagnoses (and their KC60 codes) selected for this study were syphilis (primary and secondary infectious syphilis (A1, A2)); gonorrhoea (uncomplicated gonorrhoea (B1, B2)); chlamydia (uncomplicated chlamydia (C4A, C4C)); anogenital herpes - first attack (C10A) and anogenital warts-first attack (C11A). These diagnoses were chosen based on their frequency of occurrence and their public health importance.

The unit of analysis in this study was based on an episode of infection therefore a person may be counted more than once if they presented on different occasions during the study period. Diagnoses are recorded in GUM clinics using the KC60 reporting codes that represent diagnoses, symptoms or tests, and are assigned to individuals during clinical consultation. These may underestimate the burden of disease, particularly for gonorrhoea and chlamydia but less likely for anogenital herpes and anogenital warts. An STI episode includes all diagnoses, referrals and positive test results recorded in the database with the KC60 diagnoses relevant to this study. Episode-based rates have been used in this study as it has been argued that these better represent the local burden of STI than person-based rates. ${ }^{89}$ Ethnic specific rates were not calculated due to small numbers in certain ethnic categories.

There are 21 GUM clinics in the West Midlands and, of these, two clinics did not participate in the surveillance scheme during the study period. They are, however, relatively small and contributed approximately $5 \%$ of the five selected diagnoses in 2004. KC60 data for the two clinics showed that they saw slightly more females than comparable clinics in the area but the age profiles were the same. There is no indication that their inclusion would have altered the results.

When the term "older people" is used in this paper it refers to all people aged 45 years or more. Proportions shown in the results exclude records with missing values. Episode based rates per 100000 population and their 95\% confidence intervals (95\% CI) were calculated. Denominators were the Office for National Statistics (ONS) mid-year estimates of the resident population for each year. ${ }^{10}$ Results are also presented as Rate Ratios (RR) and their $95 \%$ CI. Trend assessment was made using $\chi^{2}$ for linear trend. Data entry and data analysis were carried out using Epilnfo and SPSS statistical packages.

\section{RESULTS}

There were a total of 4445 selected diagnoses made in people aged 45 years or more between 1996 and 2003 at participating GUM clinics in the West Midlands (table 1). Genital warts comprised the largest proportion, with 45\% (1994/4445) followed by genital herpes with 19\% (862/4445).

When the percentage increase in selected diagnoses between 1996 and 2003 was compared for those aged 45 years and over with those aged less than 45 years using data from the same source, it was found that diagnoses had increased more in the older age group, and that overall an increasing proportion of STIs were reported in older people. There were 344 diagnoses in 1996 and 780 in 2003 (an increase of $127 \%, p<0.0001$ ) compared to 8848 diagnoses in 1996 and 17427 in 2003 (an increase of $97 \%, p<0.0001$ ) for those aged less than 45 years. Overall, approximately $4.5 \%(780 / 17427)$ of STIs were accounted for by older people in 2003 compared to 3.9\% (344/8848) in 1996.

\section{Temporal trends}

Between 1996 and 2003 the combined episode-based rate for all the selected diagnoses in older people was 16.7 (95\% CI 13.3 to 19.9) per 100000 population in 1996 and 36.3 (95\% CI 31.4 to 41.1) per 100000 population in 2003 (fig 1). Increases in bacterial STIs accounted largely for this increasing trend over the 8 year study period. A significantly increasing trend over time was seen overall $(p<0.0001)$ and for each of the selected diagnoses (table 1 and fig 1). Syphilis increased from 0.05 to 1.02 per 100000 population $(p<0.0001)$, gonorrhoea from 1.1 to 7.1 $(p<0.0001)$, chlamydia from 2.0 to $7.0(p<0.0001)$, anogenital warts from 9.6 to $14.6(\mathrm{p}<0.0001)$ and anogenital herpes from 4.0 to $6.6(p<0.0001)$.

\section{Sex and STI diagnoses}

Overall, men accounted for $66.8 \%$ (2959/4429) of episodes and the overall male:female ratio increased from 1.6:1 in 1996 to $2.2: 1$ in 2003. In 1996, females accounted for 39\% (133/344) of all episodes of STIs compared to $32 \%(246 / 780)$ in 2003. In both males $(p<0.0001)$ and females $(p<0.0001)$ there was a temporally significant upward trend in infection rates.

Table 1 Episodes of selected sexually transmitted infections in people aged $\geqslant 45$ years in the West Midlands, UK, by diagnostic category, sex and age group: 1996-2003

\begin{tabular}{|c|c|c|c|c|c|c|c|c|c|c|}
\hline \multirow[b]{2}{*}{ Variable } & \multicolumn{8}{|c|}{ Number of episodes* } & \multirow[b]{2}{*}{ Rate Ratio $(95 \% \mathrm{CI}) \dagger$} & \multirow[b]{2}{*}{ p Value $\chi^{2}$ for trend } \\
\hline & 1996 & 1997 & 1998 & 1999 & 2000 & 2001 & 2002 & 2003 & & \\
\hline \multicolumn{11}{|l|}{ Diagnosis } \\
\hline Chlamydia & 42 & 86 & 57 & 73 & 117 & 164 & 111 & 151 & $3.6(2.55$ to 5.06$)$ & $<0.0001$ \\
\hline Gonorrhoea & 23 & 57 & 40 & 76 & 124 & 159 & 108 & 152 & 6.61 (4.26 to 10.25 ) & $<0.0001$ \\
\hline Syphilis & 0 & 0 & 1 & 1 & 4 & 10 & 11 & 22 & $22(2.97$ to 163.2$)$ & $<0.0001$ \\
\hline Herpes & 82 & 91 & 98 & 83 & 103 & 122 & 142 & 141 & $1.72(1.31$ to 2.26$)$ & $<0.0001$ \\
\hline Warts & 197 & 217 & 231 & 229 & 248 & 304 & 254 & 314 & 1.59 (1.33 to 1.90$)$ & $<0.0001$ \\
\hline Total & 344 & 451 & 427 & 462 & 596 & 759 & 626 & 780 & 2.27 (2.00 to 2.57$)$ & $<0.0001$ \\
\hline \multicolumn{11}{|l|}{ Sex } \\
\hline Female & 133 & 175 & 159 & 149 & 175 & 225 & 208 & 246 & 1.85 (1.50 to 2.28$)$ & $<0.0001$ \\
\hline Male & 211 & 276 & 267 & 311 & 421 & 527 & 417 & 529 & 2.51 (2.14 to 2.94$)$ & $<0.0001$ \\
\hline \multicolumn{11}{|c|}{ Age group (years) } \\
\hline $45-49$ & 180 & 192 & 185 & 195 & 249 & 326 & 278 & 381 & $2.12(1.77$ to 2.53$)$ & $<0.0001$ \\
\hline $50-54$ & 82 & 134 & 128 & 132 & 179 & 187 & 179 & 208 & 2.54 (1.96 to 3.27$)$ & $<0.0001$ \\
\hline $55-59$ & 33 & 55 & 66 & 66 & 80 & 114 & 97 & 105 & $3.18(2.15$ to 4.70$)$ & $<0.0001$ \\
\hline $60+$ & 49 & 70 & 48 & 69 & 88 & 132 & 72 & 86 & $1.76(1.24$ to 2.50$)$ & $<0.0001$ \\
\hline
\end{tabular}

\footnotetext{
${ }^{*}$ Any differences between totals are due to missing information.
}

†RR: 2003 compared to 1996, or first year where a value was available. 


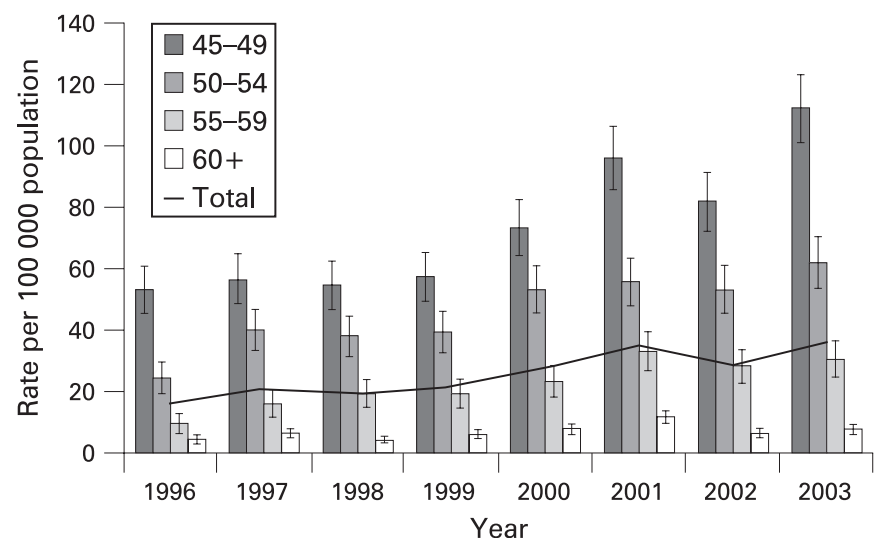

Figure 1 Rates (95\% CI) of selected sexually transmitted infections in people aged $\geqslant 45$ years in the West Midlands, UK, by year of diagnosis and age group: 1996-2003.

Episode-based rates of chlamydia have shown an upward trend for both sexes but the increase was larger in males, rising from 3.2 (95\% CI 2.1 to 4.4$)$ to 10.6 (95\% CI 8.6 to 12.6$)$ per 100000 population (fig 2).

The increase in gonorrhoea rates in males was marked, rising from 2.2 (95\% CI 1.3 to 3.1$)$ to 13.6 (95\% CI 11.4 to 15.9$)$ per 100000 population between 1996 and 2003 (fig 3). Although the number of gonorrhoea episodes in females was small, there were still seven times as many episodes in 2003 as in $1996(p<0.005)$.

An increase in episodes of infectious syphilis since 1997 was seen, particularly in men. One episode was reported in both 1998 and 1999, rising to 22 episodes in 2003. During the period 1996-2003 only four episodes of infectious syphilis were reported in older women. Ninety-one per cent (43/47) of all syphilis episodes in older persons whose gender was known were in men.

Diagnoses of the viral STIs, herpes and warts also increased amongst older males and females between 1996 and 2003. However, in both sexes the increases were smaller than those seen for bacterial STIs.

\section{Age}

The median age of older persons seen in GUM clinics was 50 years during the study period. The median age for females was

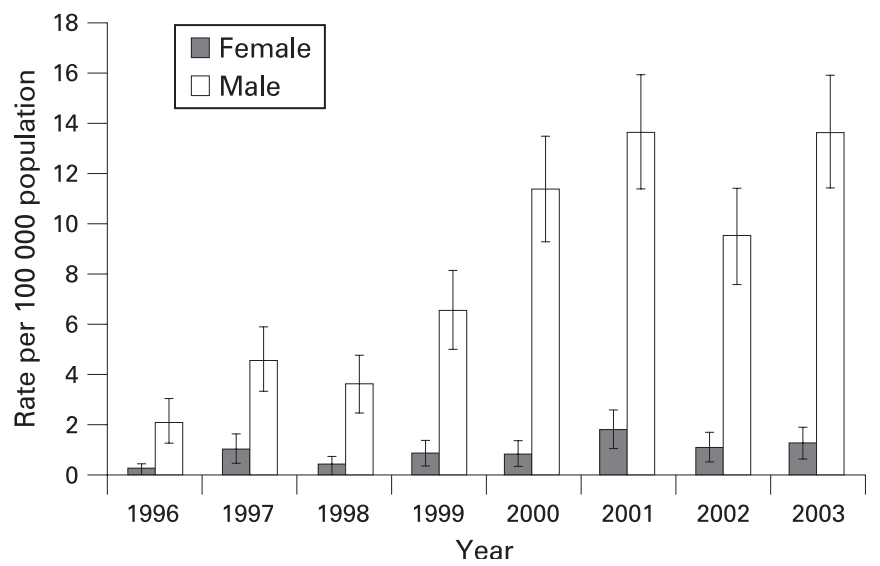

Figure 3 Rates $(95 \% \mathrm{Cl})$ of gonorrhoea infections in persons aged $\geqslant 45$ years in the West Midlands, UK, by year of diagnosis and sex: 1996-2003.

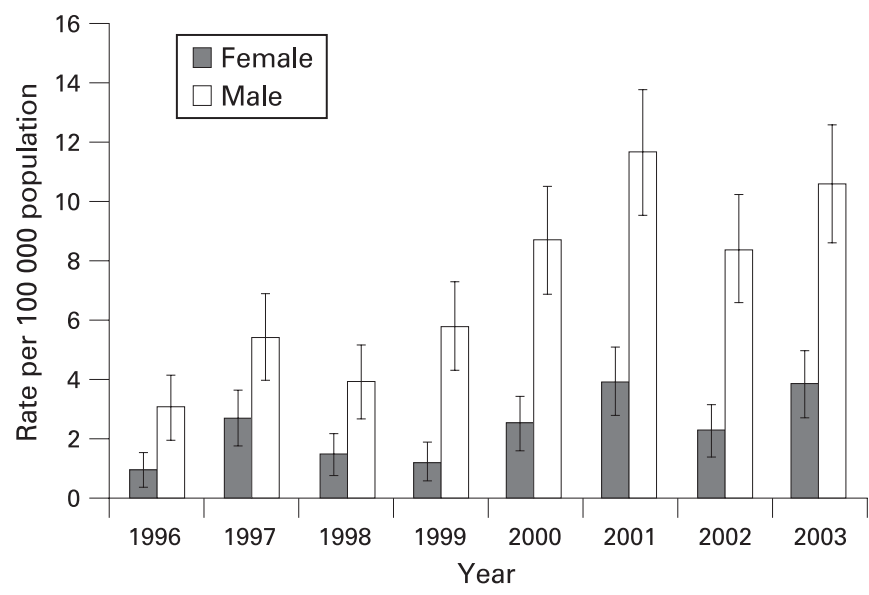

Figure 2 Rates $(95 \% \mathrm{Cl})$ of chlamydia infections in people aged $\geqslant 45$ years in the West Midlands, UK, by year of diagnosis and sex: 1996-2003.

49 years (range 45-83 years) compared to 51 years (range 45years 82 years) for males.

Overall, rates in all age groups increased significantly between 1996 and 2003 (fig 1). When comparing 2003 to the 1996 baseline, the biggest increase was seen in the 55-59 age group (RR 3.18, 95\% CI 2.15 to 4.70). Rates were higher in females in the 45-49 and 50-54 age groups, and higher in males in the 5559 and $60+$ age groups. A significantly increasing trend over time was seen for each individual age group $(p<0.0001)$.

An inverse relationship was seen between overall rates and increasing age in both males and females (fig 4).

\section{Route of infection}

Heterosexually acquired infections in males predominated for all conditions except anogenital herpes, where heterosexual females accounted for the majority of those infected. Six per cent of all the selected diagnoses were acquired homosexually. The largest proportion of homosexually acquired episodes was seen for syphilis (22\%) followed by gonorrhoea (14\%).

\section{DISCUSSION}

STIs are generally considered to predominantly affect young people and large increases in STIs have been seen in this

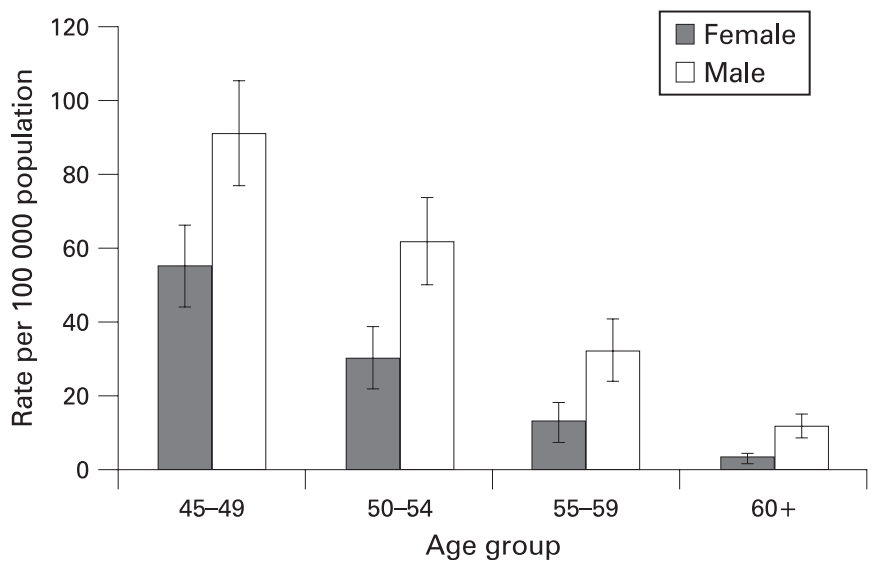

Figure 4 Rates $(95 \% \mathrm{CI})$ of selected sexually transmitted infections in people aged $\geqslant 45$ years in the West Midlands, UK, by year of sex and age group: 1996-2003. 
population in recent years. ${ }^{3}$ However, the data presented here demonstrate that these increases have been mirrored and even exceeded in older people. Although the relative numbers of STIs diagnosed in those aged 45 years and over in the West Midlands, UK, are small, the increase in rates between 1996 and 2003 was greater in those aged 45 years and over than in people aged less than 45 years.

The UK population is ageing and older people are living longer and healthier lives. There is evidence indicating that significant numbers of older people are continuing to be sexually active. ${ }^{11}$ The trends described in this report are therefore likely to continue, and may increase over time as successive cohorts with more liberal sexual attitudes and behaviours age. This will invariably lead to increased demand on available GUM clinic resources.

There is little in the scientific literature concerning STIs that is specific to those aged 45 years and over and people in this age group are often excluded from studies as researchers and policy makers focus on young people. ${ }^{12-14}$ As a consequence, information on the epidemiology as well as sexual behaviour, attitudes and knowledge in those aged 45 years and older is sparse. There are no comparable published UK studies reporting temporal trends for STIs in older people attending GUM clinics. The few available published studies are mainly cross-sectional in nature, suffer from small numbers and are not population based. ${ }^{4}{ }^{15}$ Comparable international reports on the epidemiology of STIs in older people over time are also scarce. However, national and sub-national reports from other countries support our finding that the prevalence of STIs in older people is a cause for concern. $^{9} 1617$

Age-specific data for people attending GUM clinics in the UK are collated by the HPA and they show that the overall trends reported in this study for those aged 45 years and older are reflected nationally. ${ }^{3}$ However, the HPA data do not provide a detailed age or sex breakdown and only presents data for people aged 45-64 years and 65 years or older. In our study, using a more detailed age breakdown, we have shown not only significant age differences, but also significant differences between males and females both within and between age groups. Both males and females had highest rates in the 45-49 year age group.

In order for sexual health programmes to effectively target atrisk populations, sexual health behaviour needs to be monitored. However, recent national surveys of sexual behaviour only included persons aged 16-44 years. ${ }^{12}$ Although it is acknowledged that STIs predominantly affect younger age groups, the results of this study demonstrate that older people's behaviour may also put them at risk of acquiring STIs. Indeed it may be argued that older people are more susceptible as they are less likely to use condoms than younger people. ${ }^{18}$ There is therefore a need to extend the age range of national surveys so that the sexual health needs of older people can be included.

\section{Limitations}

This study aimed to provide an overview of older people diagnosed with STIs in a defined geographical region in the UK who attend GUM clinics for care. One limitation of the data presented is that they are likely to underestimate the rate of STIs in older people as they do not include those who are reluctant to attend GUM clinics or those who seek and obtain care outside GUM clinics. However, a recent HPA report indicates that in 2006 in England and Wales the majority of diagnoses for gonococcal infection (86\%) and chlamydia (61\% in women and $85 \%$ in men) were made at GUM clinics. ${ }^{19}$
Additionally, although changes in testing practices or diagnostic methods over time may have affected the precision of the results reported for specific infections (for example, chlamydia), the overall upward trend observed during the study period reduces the possibility of bias due to any changes in diagnostic practices.

Another limitation of the study is that data regarding the total numbers of GUM attendees for each clinic were not collected, thus there is no accurate denominator. It is therefore not possible to determine whether increased attendances of older people at GUM clinics over this period could explain the increase in STIs reported. However, there was no significant net investment into the GUM services in the West Midlands in order to increase capacity within the study period and so it is an unlikely single explanation for the upward trend of STI diagnoses reported. In addition, this explanation is not generally accepted as the cause for the increasing trends observed in young people.

\section{Factors contributing to increased STIs in older people}

A number of reasons have been proposed to explain why older people are increasingly at risk of STIs, including physiological changes that occur with age and their almost universal omission from prevention programmes. ${ }^{20}$ Exclusion of older people from national programmes may be seen as stereotyping older people as being "sexually inactive". However, it may also be that the lack of a substantial evidence base on STIs in older persons has contributed to the failure of major policy initiatives such as "The National Service Framework (NSF) for the Elderly", the "National Strategy for Sexual Health and HIV" and the more recent "Choosing Health" Public Health White Paper to address the sexual health needs of older people. ${ }^{12} 21$ This paper provides quantitative data that can inform the development of sexual health policy.

Although GUM services are predominately targeted towards younger people, many older people access these services as well. However, there is evidence to suggest that older people exhibit a longer delay period between symptom recognition and GUM clinic attendance than younger people..$^{5}$ Furthermore, although older people may view GPs as their primary source of advice and care for sexual problems, both older patients and GPs have difficulty in initiating discussions about sexual health issues and risk factors for STIs/HIV. ${ }^{22}{ }^{23}$ Delay in accessing services can therefore lead to delayed diagnosis and late treatment; thereby, increasing the potential for the development of complications in the infected person as well as the continued transmission of infection to sexual partners. This suggests that older people could benefit from targeted sexual health promotion and STI prevention messages. Support for this may be drawn from studies involving older people that indicate the desire for more information about STIs; ${ }^{11}$ media sources (television and magazines) being cited as an important source of information about STIs; ${ }^{11}$ limited condom use and knowledge of STIs; ${ }^{18}$ poor perception of personal risk of STI; ${ }^{4}$ stigma associated with attending GUM clinics ${ }^{24}$ and delayed presentation for diagnosis and treatment. ${ }^{5}$

Changes in social and behavioural patterns may also have contributed to the increase in STIs seen among older people. Older people are increasingly likely to be single or undergoing relationship changes (for example, divorce, separation or widowed) and at increased risk of STIs as they are less likely to consistently use condoms. ${ }^{4}$ This may be because in this population condom use is linked with preventing unwanted pregnancy rather than prevention of STIs. Elsewhere it has been 


\section{Key messages}

- Current public health policy and sexual health programmes do not adequately cater for older people.

- This study provides evidence of significant increases in attendance at genitourinary medicine clinics by older people.

- These results indicate that sexual risk-taking behaviour is not confined to young people but also occurs among older people.

- There is a need for good quality qualitative and quantitative research to support effective planning and implementation of sexual health strategies aimed specifically at older people.

reported that both male and female international travellers are increasingly engaging in unprotected sex while travelling abroad or returning to their country of origin. Although this is mainly documented in young people, older people are not exempt. ${ }^{45}$ There is also growing evidence that the internet is being used to identify casual sexual partners by all age groups. ${ }^{26}{ }^{27}$ Meeting sexual partners over the internet is associated with increased high risk behaviour and increased risk of acquiring an STI ${ }^{28}{ }^{29}$ It is also recognised that the introduction of drugs to counter erectile dysfunction has altered the quality of life and sexual experience of older individuals. ${ }^{30}$ These drugs have the potential to increase sexual activity in older people and this, combined with the infrequent use of condoms, may contribute to increased risk of STIs. ${ }^{31}$ Overlapping sexual networks with younger people may also be a contributory factor. It is recognised that young people have multiple and at times concurrent sexual partners and that these include older people. ${ }^{32}$ Current evidence indicates that the greater the difference in age between sexual partners the more likely it is that risky sexual behaviour will occur as condoms are less likely to be used during sexual encounters. ${ }^{33} 34$

\section{CONCLUSION}

There has been a significant increase in the overall rate of STIs in older adults over the last few years, but little published research to inform public health policy, which remains youth focused. The results of this study, together with evidence from a number of other studies, would indicate that sexual risk-taking behaviour is not confined to young people but also occurs among older people. Although it is recognised that young people should remain the focus of sexual health programmes, the results of this study suggest that interventions designed to impart knowledge and provide the requisite skills needed to reduce STI risk should be provided for all sexually active age groups. Existing sexual health programmes do not adequately cater for older individuals and will require an understanding of the risk factors applicable to this sub-group of the population in order to reverse the rising trends observed in this study. There is therefore a need to support a programme of good quality (both qualitative and quantitative) research that can contribute to effective planning and implementation of intervention strategies that, while aiming to reduce STI transmission among all age groups and high risk sub-groups, include interventions aimed specifically at older people. These programmes should include strategies that encourage early diagnosis and treatment, provide age-appropriate educational materials and address societal attitudes and myths, as well as healthcare provider assumptions, regarding sexual activity among older people.

\section{What is already known on this subject?}

Sexually transmitted infections have increased in the UK over recent years and mainly affect young people (those aged $<25$ years). Sexual health strategies rightly focus on this age group; however, little attention has been paid to older people (those $\geqslant 45$ years).

\section{What this study adds}

This study addresses an area where little published epidemiological data are available and has identified significant increases in attendance at genitourinary medicine clinics by those 45 years or older. This indicates that "safe sex" messages and sexual health research should target all sexually active members of the population, including older people.

Acknowledgements: This work would not have been possible without the assistance of the Genitourinary Medicine (GUM) clinics and their staff. Collaborating GUM clinics: Arrowside Centre, Redditch Alexandra Hospital (Dr S Bhaduri); Coventry \& Warwickshire Hospital GUM Department (Dr A Wade, Dr S Allen, Dr S Das); Dartmouth Clinic, Sandwell DGH (Dr T Ray); Delia Morris Centre, Burton-On-Trent (Dr C Murray); Dudley Guest Hospital GUM Department (Dr A El Dalil); Gaol Street Sexual Health Clinic, Hereford (Dr C Okereke); George Eliot Hospital GUM Dept, Nuneaton (Dr M Walzman); Hawthorn House, Birmingham Heartlands Hospital (Dr D White, Dr S Taylor); Jephson Centre, Warwick Hospital (Dr D Natin); Rugby Hospital of St Cross GUM Department (Dr L David); Royal Shrewsbury Hospital GUM Department (Dr S Devendra); Stratford Upon Avon Hospital GUM Department

(Dr D Natin); Tamworth Sir Robert Peel Hospital GUM Department (Dr J Fernando); Telford Princess Royal Hospital GUM Department (Dr S Devendra); University Hospital of North Staffordshire GUM Department (Dr S Sivapalan, Dr G Singh); Walsall Manor Hospital GUM Department (Dr J Arumainayagam); Whittall Street Clinic, Birmingham (Prof J Ross, Dr K Radcliffe, Dr M Shamanesh, Dr M Huensberg, Dr P Goold, Dr K Manavi); Wolverhampton New Cross Hospital GUM Department (Dr A Tariq); and Worcester John Anthony Centre (Dr Y DaSilva, Dr M Roberts).

Competing interests: None.

Contributors: $A B-T$ and $B 0$ conceived the study. All authors contributed to the design of the study and data collection. All authors contributed to analysis and interpretation of data. All authors critically reviewed and contributed to the final draft of the paper and approved the final version for publication. BO is the guarantor.

\section{REFERENCES}

1. Department of Health. The National Strategy for Sexual Health and HIV. London: Department of Health, 2001.

2. Department of Health. Choosing Health: Making Healthier Choices Easier. London: Department of Health, 2004.

3. Health Protection Agency. Diagnoses of selected STIs by Strategic Health Authority, country, sex and age group, United Kingdom: 1997-2006. http://www. hpa.org.uk/webc/HPAwebfile/HPAweb_C/1206003520175 (accessed 22 April 2008)

4. Jaleel H, Allan S, Wade AAH. Sexually transmitted infections in the elderly. Sex Transm Inf 1999;75:449.

5. David N, Rajmanoharan S, Tang A. Sexually transmitted infections in elderly people. Sex Transm Inf 2002; 76:222

6. Blair I, Bodley-Tickell AT, Bhaduri S, et al. Surveillance of sexually transmitted infections in the West Midlands using anonymised individual patient data sets from genitourinary medicine clinics. Commun Dis Public Health 2004;7:112-19.

7. PHLS Communicable Disease Surveillance Centre. Quarterly Communicable Disease Review October to December 2001: Caldicott, Confidentiality and the Patient Information Advisory Group. J Public Health Med 2002;24:138-44.

8. Low N, Sterne JA, Barlow D. Inequalities in rates of gonorrhoea and chlamydia between black ethnic groups in south east London: cross sectional study. Sex Transm Infect 2001;77:15-20.

9. Xu F, Schillinger JA, Aubin MR, et al. Sexually transmitted diseases of older persons in Washington State. Sex Transm Dis 2001;28:287-91.

10. National Statistics. Population Estimates for UK, England and Wales, Scotland and Northern Ireland. http://www.statistics.gov.uk/statbase/Product. asp? $\mathrm{vInk}=601$ \&More $=\mathrm{N}$ (accessed 5 March 2008).

11. Gott CM. Sexual activity and risk-taking in later life. Health Soc Care Community 2001;9:72-8. 
12. Johnson AM, Mercer $\mathbf{C H}$, Erens $\mathrm{B}$, et al. Sexual behaviour in Britain: partnerships, practices, and HIV risk behaviours. Lancet 2001;358:1835-42.

13. Connor N, Catchpole M, Rogers PA, et al. Sexually transmitted diseases among teenagers in England and Wales. Commun Dis Rep CDR Rev 1997;7:R173-8.

14. Finer LB, Darroch JE, Singh S. Sexual partnership patterns as a behavioral risk factor for sexually transmitted diseases. Fam Plann Perspect 1999:31:228-36.

15. Cranston RD, Thin RN. How common are sexually transmitted infections in the elderly? Sex Transm Infect 1998; 74:379.

16. Tan HH, Chan RKW, Goh CL. Sexually transmitted diseases in the older population in Singapore. Ann Acad Med Singapore 2002;31:493-6.

17. Chen X-S, Gong X-D, Liang G-J, et al. Epidemiologic trends of sexually transmitted diseases in China. Sex Transm Dis 2000;27:138-42.

18. Murphree DD, DeHaven MJ. Does grandma need condoms? Condom use among women in a family practice setting. Arch Fam Med 1995;4:233-8.

19. Health Protection Agency. Testing times - HIV and other sexually transmitted infections in the United Kingdom: 2007. http://www.hpa.org.uk/web/ HPA\&HPAwebstandard/HPAweb_c/1203084355941 (accessed 22 April 2008).

20. Mahar F, Sherrard J. Sexually transmitted infections. In Rees M, Mander T, eds. Sexual health and the menopause. The Royal Society of Medicine, 2005.

21. Department of Health. National Service Framework for Older People. London: Department of Health, 2001

22. Gott $\mathbf{M}$, Hinchliff S. Barriers to seeking treatment for sexual problems in primary care: a qualitative study with older people. Fam Pract 2003:20:690-5.

23. Verhoeven V, Bovijn K, Helder A, et al. Discussing STls: doctors are from Mars, patients from Venus. Fam Pract 2003;20:11-15.
24. Gott CM, Rogstad KE, Riley V, et al. Delay in symptom presentation among a sample of older GUM clinic attenders. Int J STD AIDS 1999;10:43-6.

25. Carter S, Horn K, Hart G, et al. The sexual behaviour of international travellers at two Glasgow GUM clinics. Glasgow genitourinary medicine. Int J STD AIDS 1997;8:336-8.

26. Rietmeijer CA, Bull SS, McFarlane M, et al. Risks and benefits of the internet for populations at risk for sexually transmitted infections (STIs): results of an STI clinic survey. Sex Transm Dis 2003;30:15-19.

27. McFarlane $\mathbf{M}$, Bull $\mathrm{S}$, Rietmeijer $\mathbf{C}$. The Internet as a newly emerging risk environment for sexually transmitted diseases. JAMA 2000;284:443-6.

28. Bolding G, Davis M, Hart G, et al. Heterosexual men and women who seek sex through the Internet. Int J STD AIDS 2006;17:530-4.

29. McFarlane M, Kachur R, Bull S, et al. Women, the internet, and sexually transmitted infections. J Womens Health 2004;13:689-94.

30. Potts A, Grace V, Gavey N, et al. "Viagra stories": challenging 'erectile dysfunction'. Soc Sci Med 2004;59:489-99.

31. Paniagua FA. Commentary on the possibility that Viagra may contribute to transmission of HIV and other sexual diseases among older adults. Psychol Rep 1999;85:942-4

32. Ford K, Sohn W, Lepkowski J. American adolescents: sexual mixing patterns, bridge partners, and concurrency. Sex Transm Dis 2002;29:13-19.

33. Darroch JE, Landry DJ, Oslak S. Age differences between sexual partners in the United States. Fam Plann Perspect 1999;31:160-7.

34. Gregson S, Nyamukapa CA, Garnett GP, et al. Sexual mixing patterns and sexdifferentials in teenage exposure to HIV infection in rural Zimbabwe. Lancet 2002;359:1896-903.

\section{Keep up to date: sign up for our alerting services}

Find out automatically when an article is published on a specific topic or by a particular author. We can also alert you when an article is cited or if an eLetter or correction is published. You can also choose to be alerted when a new issue is published online [and when we post articles Online First]. Check out the New Content Alerts and Citation tracker from the Online tools section on the home page. 